\title{
Infectious Agents Identified by Real-Time PCR, Serology and Bacteriology in Blood and Peritoneal Exudate Samples of Cows Affected by Parietal Fibrinous Peritonitis after Caesarean Section
}

\author{
Salem Djebala ${ }^{1, *(\mathbb{C}}$, Julien Evrard ${ }^{2}$, Fabien Gregoire ${ }^{2}$, Damien Thiry $\left.{ }^{3}{ }^{(}\right)$, Calixte Bayrou ${ }^{1}(\mathbb{D}$, \\ Nassim Moula ${ }^{4}{ }^{\mathbb{D}}$, Arnaud Sartelet ${ }^{1}$ and Philippe Bossaert ${ }^{1}$ \\ 1 Clinical Department of Ruminants, University of Liège, Quartier Vallée 2, Avenue de Cureghem 7A-7D, \\ 4000 Liège, Belgium; Calixte.Bayrou@uliege.be (C.B.); asartelet@uliege.be (A.S.); p.bossaert@uliege.be (P.B.) \\ 2 Gestion et Prévention de Santé, Regional Association of Health and Animal Identification, Allée des \\ Artisans 2, 5590 Ciney, Belgium; julien.evrard@arsia.be (J.E.); fabien.gregoire@arsia.be (F.G.) \\ 3 Bacteriology, Department of Infectious and Parasitic Diseases, University of Liège, Quartier Vallée 2, \\ Avenue Cureghem 6, B-4000 Liège, Belgium; damien.thiry@uliege.be \\ 4 Department of Animal Production, University of Liege, Quartier Vallée 2, Avenue de Cureghem 6, \\ 4000 Liège, Belgium; nassim.moula@uliege.be \\ * Correspondence: sdjebala@uliege.be; Tel.: +32-4-93-33-359
}

Received: 23 August 2020; Accepted: 10 September 2020; Published: 13 September 2020

\begin{abstract}
The aim of this study was to identify the pathogens potentially involved in parietal fibrinous peritonitis (PFP). PFP is a complication of laparotomy in cattle, characterized by an accumulation of exudate inside a fibrinous capsule. We have studied 72 cases of PFP in Belgian blue cows, confirmed by a standard diagnostic protocol. Blood was collected to evaluate the presence of antibodies for Mycoplasma bovis (M. bovis), Coxiella burnetii (C. burnetii) and Bovine Herpesvirus 4 (BoHV4) by enzyme-linked immunosorbent assays. Peritoneal exudate was obtained from the PFP cavity to perform bacteriological culture, and to identify the DNA of M. bovis, C. burnetii and BoHV4 using real time polymerase chain reaction (qPCR). Bacteriological culture was positive in most peritoneal samples (59/72); Trueperella pyogenes (T. pyogenes) (51/72) and Escherichia coli (E. coli) (20/72) were the most frequently identified. For BoHV4, the majority of cows showed positive serology and qPCR (56/72 and 49/72, respectively). Contrariwise, $M$. bovis (17/72 and 6/72, respectively) and C. burnetii $(15 / 72$ and $6 / 72$, respectively) were less frequently detected $(p<0.0001)$. Our study proves that PFP can no longer be qualified as a sterile inflammation. Moreover, we herein describe the first identification of BoHV4 and C. burnetii in cows affected by PFP.
\end{abstract}

Keywords: Parietal fibrinous peritonitis; caesarean section; peritoneal fluids; Coxiella burnetii; Bovine Herpesvirus 4; Mycoplasma bovis; Trueperella pyogenes; Escherichia coli

\section{Introduction}

Parietal fibrinous peritonitis (PFP) in cattle is a postoperative complication of laparotomy [1-3], characterized by the accumulation of fibrin and peritoneal exudate inside a thick fibrous capsule between the outer sheath of the parietal peritoneum and the abdominal muscular layers [1,3]. Symptoms of PFP occur several weeks after surgery, and may include hyperthermia, anorexia, weight loss, visual abdominal distention, and colic [3-5].

In Belgium, PFP is frequently encountered in rural veterinary practice due to the large number of elective caesarean sections (CS) performed in the Belgian Blue breed [6]. Its incidence after CS has been 
estimated to be $1 \%$, and its mortality has been estimated at $13 \%[7,8]$. Unfortunately, PFP is very scarcely documented and rural practitioners have little information considering its treatment, prevention and prognosis. In particular, the aetiology of PFP is the subject of speculation. For a long time, PFP has been considered as an aseptic inflammation $[5,8,9]$. This assumption has recently been challenged, after the isolation of several aerobic and anaerobic bacteria such as Trueperella pyogenes (T. pyogenes), Escherichia coli (E. coli), Staphylococcus aureus, Pseudomonas aeruginosa, Proteus mirabilis, Fusobacter necrofurum, Comamonas kerstersii, Bacillus licheniformis, and Bacteroides species in in the peritoneal fluid of PFP cows [2-4].

The last decade, three infectious agents have received ample attention in Belgian rural practice, i.e., Mycoplasma bovis (M. bovis), Coxiella burnetii (C. burnetii) and Bovine Herpesvirus 4 (BoHV4). All three germs have been identified in various bovine infectious disorders including reproductive tract disease, abortion, mastitis, respiratory diseases, and arthritis [2,10-12], and the number of positive laboratory diagnoses shows an increasing trend $[13,14]$. Their implication in peritonitis and PFP is unclear.

The aim of this study was to perform bacteriological culture on peritoneal fluid samples of a large cohort of cows presenting PFP. Furthermore, to gain a broader insight into the aetiology of PFP, we aimed to evaluate the implication of M. bovis, C. burnetii and BoHV4 in PFP, by determining the presence of antibodies in the blood and genetic material in peritoneal fluid samples from cows presenting PFP.

\section{Material and Methods}

Between March 2017 and March 2018, the Clinical Department of Production Animals (University of Liege in Belgium) and the Regional Association of Animal Health and Identification (ARSIA) collaborated with Belgian rural veterinary practitioners in a project to obtain diagnostic elements on PFP in Belgian blue cattle breed. All rural veterinarians from the ARSIA database were contacted by e-mail, and instructions for the diagnosis and treatment of PFP were published online. In each case suspected of PFP based on clinical signs and ultrasound findings, an aseptical paracentesis of the cavity was carried out to confirm the diagnosis, as described in previous studies [3,4]. Finally, PFP was confirmed in 72 cases, and $10 \mathrm{~mL}$ of peritoneal fluid was collected in each case for further examination. Furthermore, blood samples were obtained from the coccygeal vein using non-coagulant Vacutainer ${ }^{\circledR}$ tubes (BD, Plymouth, UK) for biochemical analysis, and an additional blood tube was collected for further examination of the serological status of the animals. Finally, the treatment (and definitive diagnosis) consisted of surgical draining of the PFP cavity. All blood and peritoneal fluid samples were kept at $4{ }^{\circ} \mathrm{C}$ and dispatched to the ARSIA laboratory. The national identification database (SANITEL) was consulted afterwards for the cattle age. Consent was obtained from all veterinarians and owners to use the samples to perform the current study and publish the results.

All invasive procedures (paracentesis, blood sampling and surgical drainage) were done in cases encountered in the field, primarily for diagnostic and therapeutic purposes. At no point did the research protocol interfere with treatment decisions and housing or management of the cows. Therefore, the animals in our study did not fall into the definition of an experimental animal, and no ethical approval was required.

Peritoneal exudate samples were used for aerobic and anaerobic bacteriological culture and for the detection of $C$. burnetii, M. bovis and BoHV4 genetic material. Blood samples were used for the detection of $C$. burnetii, $M$. bovis and BoHV4 antibodies.

The samples for aerobic culture were grown on Columbia agar, Gassner and Columbia/Nalidixic acid agar media (Thermo Fisher Scientific, Brussels, Belgium) at $37 \pm 2{ }^{\circ} \mathrm{C}$. Samples for anaerobic culture were grown under anaerobic conditions on Schaedler medium (Thermo Fisher Scientific, Brussels, Belgium) at $37 \pm 2{ }^{\circ} \mathrm{C}$. Two readings of each medium were performed at 18 to $24 \mathrm{~h}$ and 36 to $48 \mathrm{~h}$ of incubation. Bacterial identification was performed by the Maldi Biotyper ${ }^{\circledR}$ (Bruker Daltonics, Bremen, Germany). The culture was considered "negative" if no bacterial growth was observed, and "positive" when one or several bacteria were found. 
The detection of $M$. bovis, $C$. burnetii and BoHV4 antibodies was performed using commercially available enzyme-linked immunosorbent assay (ELISA) kits: Monoscreen AbELISA BoHV-4 indirect bicupule (Bio K263) ${ }^{\circledR}$ (BioX, Rochefort, Belgium), Monoscreen AbELISA Mycoplasma bovis indirect monocupule (Bio K302) ${ }^{\circledR}$, (BioX, Rochefort, Belgium) and PrioCHECK ${ }^{\mathrm{TM}}$ Ruminant Q Fever Ab Plate Kit (ELISACOXLS) ${ }^{\circledR}$ (Thermo Fisher Scientific, Rochefort, Belgium).

The ELISA test results of BoHV4 and C. burnetii are semi-quantitative. The antibody concentration $(\%)$ is calculated as the ratio between the optic density of the tested sample and a control sample, multiplied by 100. Results for BoHV4 and C. burnetii were classified as "negative" (relative density below 30\% and 40\%, respectively), as "positive" (relative density between $30 \%$ and $120 \%$ and between $40 \%$ and $300 \%$, respectively) or as "highly positive" (relative density above 120\% and above 300\%, respectively). The results for the $M$. bovis ELISA kit are only qualitative ("positive" or "negative").

The presence of genetic material of M. bovis, C. burnetii and BoHV4 was analyzed in peritoneal fluids samples using real time polymerase chain reaction (qPCR). The DNA extraction was achieved using MagAttract 96 cador Pathogen Kit ${ }^{\circledR}$ (QIAGEN, Antwerp, Belgium) and an extraction robot KingFisher ${ }^{\mathrm{TM}}$ Flex $96^{\circledR}$ (Thermo Fisher Scientific, Brussels, Belgium), according to the manufacturer's instructions. Three commercially available kits were used: LSI VetMAX Bovine Herpes Virus Type $4^{\circledR}$ (Thermo Fisher Scientific, Brussels, Belgium), LSI VetMAX Mycoplasma bovis ${ }^{\circledR}$ (Thermo Fisher Scientific, Brussels, Belgium) and LSI VetMAX Coxiella burneti-Absolute Quantification ${ }^{\circledR}$ (Thermo Fisher Scientific, Brussels, Belgium). Thermal cycling conditions were controlled using Thermocycleur ABI7500 ${ }^{\circledR}$ (Thermo Fisher Scientific, Brussels, Belgium). A "negative", "positive" or "highly positive" result was obtained, corresponding to replication cycles $(\mathrm{Ct})$ below 45, between 45 and 30, or below 30 , respectively.

Statistical analyses were performed using SAS (2001). Descriptive analysis was carried out for the age of cows and the number of bacteria cultured in the peritoneal exudate. Continuous data (age, number of bacteria found by bacteriology) were checked for normal distribution with a Shapiro-Wilk test, and displayed as the median and range in case of non-normal distribution. Chi-square and Fisher tests were used to compare the number of positive and negative results of bacteriological culture, ELISA and qPCR, and to compare the germ-specific proportions within positive samples of bacteriology, ELISA and qPCR. Moreover, a Chi-square test was used to compare the antibody and DNA concentration in the positive, semiquantitative samples. A test of independence was performed to evaluate the relation between ELISA and qPCR outcomes and the results of bacterial culture. The procedure "Proc Freq" in SAS was used for all statistical analyses; the cut-off of significance was fixed at $p<0.05$.

\section{Results}

In total, 37 rural veterinarians collected blood and peritoneal exudate samples from 72 cows affected by PFP after CS in 61 Walloon farms. The age of cows affected by PFP varied from 26 to 120 months with a median of 45 months.

Bacteriology was positive in the majority (59/72) of cows and negative in only 13/72 samples $(p<0.0001)$. The number of bacteria identified in the positives samples varied between 1 to 3 with a median of 1 .

In total, 82 different strains from nine bacteria species were identified in the positive samples, among which T. pyogenes (51/59) and E. coli (20/59) were predominant compared to the other sporadically identified bacterial species ( $p<$ in the remaining samples). E. coli was identified alone in $4 / 20$ samples and in association with other bacteria in the other $16 / 20$ peritoneal samples, especially T. pyogenes. The other isolated bacteria species were always associated with T. pyogenes or E. coli, except for Helicoccus ovis and Streptococcus mitis, which were identified alone. Aerobic bacteria were more frequently identified than anaerobic ( $p<0.0001)$; at least one aerobic bacteria (mainly T. pyogenes and E. coli) was cultured in all positive samples (59/59), while anaerobic bacteria (exclusively Clostridium perfringens) were observed in 
only 4/59 samples and were always associated with aerobic bacteria. All the results of bacteriological culture are summarized in the Scheme 1.

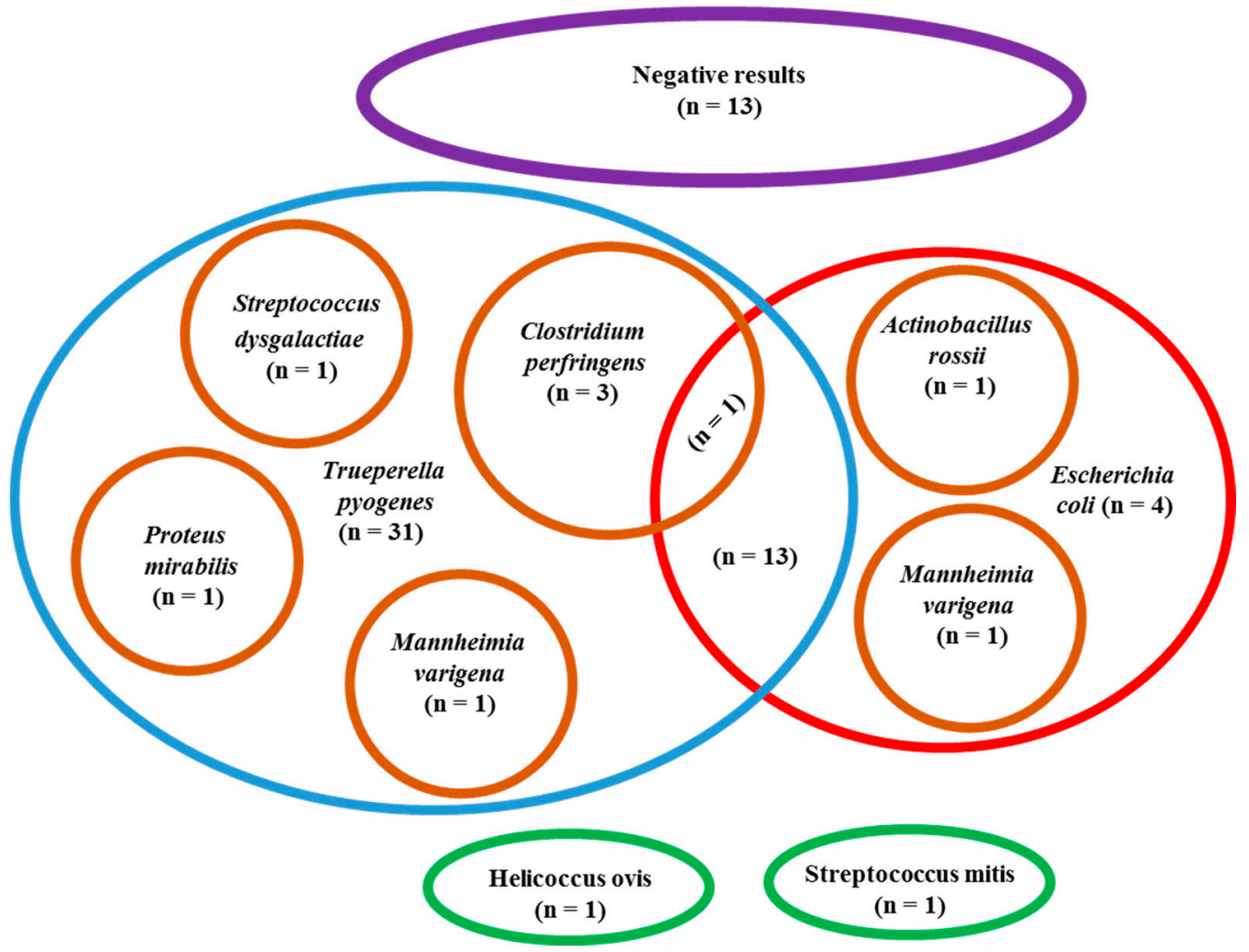

Scheme 1. Results of bacteriological culture performed in peritoneal exudate samples of 72 cows affected by parietal fibrinous peritonitis, with specific focus on the 51 positive samples for Trueperella pyogenes and 20 positive samples for Escherichia coli.

Antibodies against at least one of three germs were detected in the majority of blood samples (61/72); only 11/72 were fully negative $(p<0.0001)$. Antibodies of BoHV4 were the most frequently detected (56/72), compared to those of C. burnetii $(15 / 72)$ and M. bovis $(17 / 72)(p<0.0001)$. The majority of positive C. burnetii (14/15) and M. bovis (13/17) serology results were associated with a positive BoHV4 ELISA. Within the positive samples, the concentration of BoHV4 antibodies was "highly positive" in most cases (53/56), and "positive" for the other samples $(3 / 56)(p=0.002)$. Within positive ELISA results for C. burnetii, concentrations were "positive" in all cases, and never "highly positive". Details of the ELISA results are displayed in Scheme 2.

The details of qPCR results for the different germs are displayed in Scheme 2. The qPCR analysis for BoHV4, C. burnetii and M. bovis confirmed the genetic material of at least one germ in the majority of samples $(52 / 72)$, while 20/72 were completely negative $(p=0.0001)$. Genetic material of BoHV4 was identified most frequently in peritoneal exudate (49/72) compared to C. burnetii (6/72) and M. bovis $(6 / 72)(p<0.0001)$. Furthermore, C. burnetii $(3 / 6)$ and M. bovis DNA $(6 / 6)$ were in most cases found in combination with BoHV4. The quantity of BoHV4 genetic material was "highly positive" in most peritoneal samples (30/49), and "positive" in the other positive samples (19/49) $(p=0.116)$. The level of "highly positive" was reached in none of the positive C. burnetii samples, and in only $1 / 6$ M. bovis samples. 


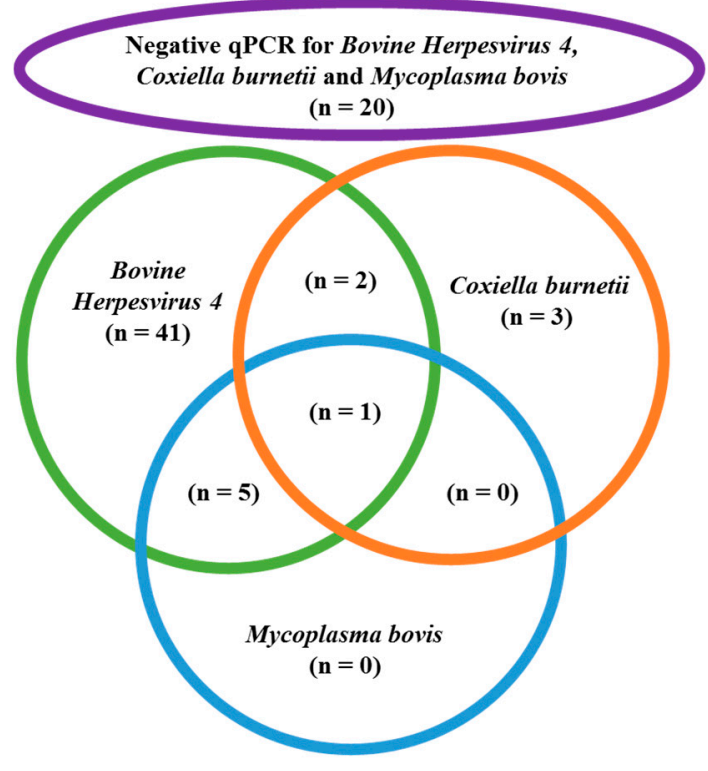

(A)

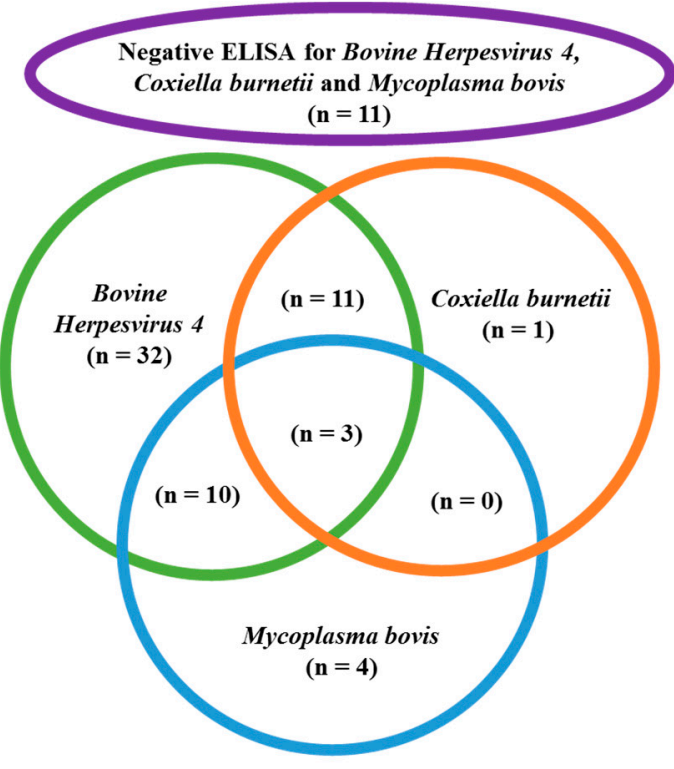

(B)

Scheme 2. ELISA and qPCR results of cows affected by parietal fibrinous peritonitis: (A) Results of germ DNA identified by qPCR in peritoneal exudate samples of 72 cows affected by parietal fibrinous peritonitis, with a specific focus on the 49 positive samples for Bovine Herpesvirus 4. (B) Results of antibody identified by ELISA in blood samples of 72 cows affected by parietal fibrinous peritonitis, with specific focus on the 56 positive samples for Bovine Herpesvirus 4.

For $\mathrm{BoHV}$, the results of ELISA corresponded to those of qPCR in the majority of cases. In other words, in most cows having a negative serology for BoHV4, a negative qPCR was found, and the positive QPCR results corresponded with a positive serology. In rare cases, a positive ELISA result was found in combination with a negative GPCR, or vice versa. For C. burnetii and M. Bovis, a negative result for qPCR and ELISA was observed in the majority of cases. In contrast to BoHV4, several discrepancies between ELISA and qPCR were found; the majority of ELISA positive samples were negative to qPCR, while around half of qPCR positive samples were ELISA negative. The combination of qPCR and ELISA results for the three targeted germs is displayed in Table 1.

Table 1. Combined results of blood antibodies detected by ELISA and germs DNA identified by qPCR (peritoneal sample) for Bovine Herpesvirus 4, Coxiella burnetii and Mycoplasma bovis in 72 cows affected by parietal fibrinous peritonitis.

\begin{tabular}{|c|c|c|c|}
\hline \multirow{2}{*}{\multicolumn{2}{|c|}{ Results of qPCR and ELISA of the Three Searched Germs. }} & \multicolumn{2}{|c|}{ qPCR } \\
\hline & & Positive & Negative \\
\hline \multicolumn{4}{|c|}{ Bovine Herpesvirus 4} \\
\hline \multirow{2}{*}{ ELISA } & Positive & 45 & 11 \\
\hline & Negative & 4 & 12 \\
\hline \multicolumn{4}{|c|}{ Coxiella burnetii } \\
\hline \multirow{2}{*}{ ELISA } & Positive & 2 & 13 \\
\hline & Negative & 4 & 53 \\
\hline \multicolumn{4}{|c|}{ Mycoplasma bovis } \\
\hline \multirow{2}{*}{ ELISA } & Positive & 3 & 14 \\
\hline & Negative & 3 & 52 \\
\hline
\end{tabular}

A positive statistical association was found between the qPCR and ELISA results for BoHV4 and bacteriological culture results. This relation between $\mathrm{QPCR}$ and ELISA results and bacteriological 
culture results could not be confirmed in the case of C. burnetii or M. bovis. The combinations of qPCR and ELISA results and bacteriology outcomes are displayed in Scheme 3.
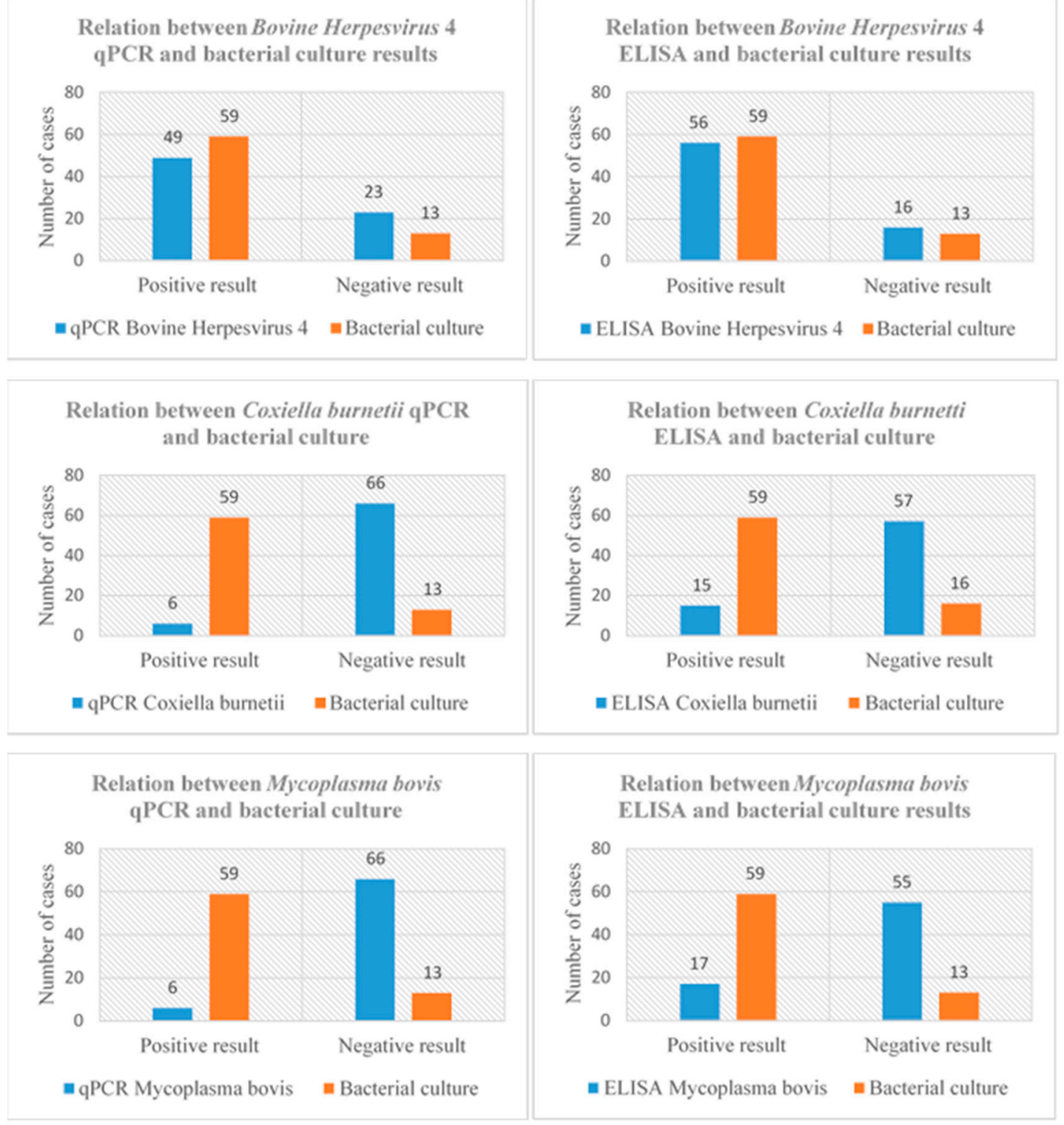

Scheme 3. Relation between blood antibodies identified by ELISA and germs DNA identified by qPCR (peritoneal samples) for Bovine Herpesvirus 4, Coxiella burnetii and Mycoplasma bovis, and the bacteriological culture results (peritoneal samples) of 72 cows affected by parietal fibrinous peritonitis.

\section{Discussion}

This study presents a unique dataset containing a large number of PFP cases observed in the field. Only very few studies have reported aerobic or anaerobic bacteria, BoHV4 and M. bovis in peritoneal liquids and, particularly, in cases of PFP $[2-4,15]$. To our knowledge, the presence of $C$. burnetii in peritoneal fluids has never been demonstrated.

At least one bacterial species was cultured in more than $80 \%$ of the tested samples in this study. This number may even be an underestimation of the true presence, due to the limited sensitivity of bacteriological culture. Also, it is very likely that several cows had been treated with antimicrobials before sampling, modifying the culture results $[2,4,16,17]$. 
In a previous publication, anaerobic bacteria have been mainly isolated from the peritoneum during CS [18]. This led to the assumption that bacteria originating from the endogenous vaginal flora and the incised uterus were the main contaminants leading to infectious complications after CS. In the current study, in contrast, aerobic bacteria were isolated far more frequently from PFP than anaerobic germs. T. pyogenes and E. coli were predominant, confirming earlier reports on PFP and generalized peritonitis [3].

T. pyogenes and E. coli are ubiquitous in the environment $[19,20]$ and colonize a wide range of tissues and organs [20-22]. Hence, it seems logical that exogenous contamination by T. pyogenes and E. coli during CS is a primary cause of infectious complications, including PFP and peritonitis [23-25]. Evidently, the risk of complications increases in the case of a massive contamination or immunosuppression $[22,26,27]$. On the other hand, since healthy cows can have a physiological bacteraemia [21], it is also plausible that PFP is the result of secondary haematogenous infection of a sterile fluid-filled cavity. In conclusion, PFP is in the majority of cases bacterially contaminated, but it remains to be elucidated whether bacteria are primary agents of PFP originating from the environment, the surgeon's hands, the surgical material or the cow's skin or organs $[19,20,22]$, or secondary contaminants of an initially sterile process.

A large number of cows suffering from PFP displayed a positive serology and/or qPCR for one or more of three emerging pathogens, i.e., BoHV4, C. burnetti and M. bovis. These three germs can invade multiple tissues [13] and share the potential to invade white blood cells, allowing them to escape the host's immune response and to pass into a dormant phase [28-30]. Stress, parturition and inflammatory processes can reactivate a dormant infection $[2,29,31]$. Hence, their presence in the PFP fluids may be the result of haematogenous spread via immune cells toward an inflammatory site, and their true implication in the pathogenesis of PFP remains to be elucidated.

The combination of serology and qPCR results allows some interpretation. Animals with an active infection will typically have a positive serology and high amounts of DNA in the infection site $[14,32,33]$. A positive qPCR in the absence of blood antibodies is indicative of a recent infection; the time between primary infection and detectable antibody levels ranges from 10 days to 4 weeks for the three germs $[29,32,34]$. A negative qPCR in the presence of antibodies indicates an inactive infection, inhibition of reactivation by a serologic response [29,33,34], or intermittent bacterial replication [35]. There is a long persistence of antibodies in blood circulation after primary infection $[2,36]$.

Of the three studied germs, BoHV4 yielded the most positive results: over $75 \%$ of blood samples were seropositive. This is in line with the endemic situation of this virus in Belgian herds, particularly in beef cattle and older cows [14,37]. For comparison, the seroprevalence has been reported to be $67.5 \%$ in aborting cows in Wallonia [14]. Nearly $70 \%$ of peritoneal fluids were highly positive for qPCR, mostly in association with a strongly positive serology, indicating an active or reactivated infection. A negative qPCR in combination with a (highly) positive ELISA result was observed in a small number of cases, indicating latency of the virus and a serological response. Since a direct relation between BoHV4 detection and specific lesions has never been established [38], the relevance of BoHV4 in the pathogenesis of PFP remains unclear.

Antibody or DNA detection for C. burnetii and M. bovis yielded far fewer positive results than BoHV4. C. burnetii and M. bovis are common in Belgium: $57.8 \%$ of tested herds in Wallonia have been reported to have seropositive animals for C. burnetti, and 30\% of herds contain animals actively excreting the germ [33]. Between 2012 and 2016, the apparent herd seroprevalence for M. bovis has been estimated to be $23.6 \%$ [13]. The combination of a negative serology and a negative qPCR in peritoneal fluid was most frequently found. A positive ELISA in combination with a negative qPCR was detected in a number of cases, indicating an inactive infection or a serological inhibition of reactivation $[29,33]$. As for M. bovis, this may also be due to the intermittent bacterial replication [35].

A positive association was observed between the presence of BoHV4 (DNA and/or antibodies) and the bacteriological results. Moreover, C. burnetii and M. bovis antibodies and DNA were rarely found alone, as reported elsewhere [36,39], and were almost always associated with BoHV4 antibodies and 
DNA. It can be postulated that a decrease of immunity induced by a BoHV4 infection may increase the risk of bacterial co-infection $[28,38,40,41]$. Inversely, the inflammatory condition caused by bacterial infection might also induce $\mathrm{BoHV} 4$ reactivation $[40,41]$.

It should be stressed that the presence of germs, their genetic material or their antibodies in PFP cows does not prove a causal mechanism. Their exact role in the pathogenesis of PFP requires further studies. The presence of peritoneal fluids in matched negative control cows could have shed more light on the importance of a positive bacteriology or qPCR, but this was not feasible in the current study setup.

\section{Conclusions}

PFP is a frequent pathology in Belgium. Our study clearly demonstrates that PFP can no longer be considered as a sterile process. Our study confirms previous reports of $M$. bovis in the peritoneal fluid of cows presenting PFP and adds the PFP as new target sites for BoHV4, C. burnetii and other bacterial species. These germs can colonize the PFP through endogenous and exogenous contaminations of CS or via haematogenous spread. Their exact role in the pathogenesis of PFP cannot be concluded from this dataset and requires further studies.

Author Contributions: S.D., J.E., F.G., D.T., C.B., N.M., A.S., P.B. assisted in study design, data analysis and manuscript preparation. S.D., J.E., F.G., A.S., P.B. gathered samples and did data collection. J.E., F.G. supervised the laboratory work. N.M., C.B., A.S., P.B. supervised the scientific quality. All authors have read and agreed to the published version of the manuscript.

Funding: This research: and especially the laboratory analysis, was financed by the Walloon cattle monitoring project ("GPS bovin") headed by the regional association for animal identification and health (Wallonie/ARSIA).

Acknowledgments: We would like to thank the rural veterinarians and farmers who have participated in the data collection and everyone who contributed to the correction and the improvement of the manuscript.

Availability of Data and Materials: The main data are presented in the paper. However, raw data files can be provided upon request.

Ethics Approval and Consent to Participate: Consent was obtained from all owner to use blood and peritoneal exudate for this study. Sampling was generally done by the veterinarian, following established guidelines and adherent to the high standards of veterinary care.

Consent for Publication: Not applicable.

Competing Interests: The authors declare that they have no competing interests.

Conflicts of Interest: The authors declare no conflict of interest.

\section{References}

1. Braun, U.; Pusterla, N.; Anliker, H. Ultrasonographic findings in three cows with peritonitis in the left flank region. Vet. Rec. 1998, 142, 338-340. [CrossRef] [PubMed]

2. Gille, L.; Pilo, P.; Valgaeren, B.R.; van Driessche, L.; van Loo, H.; Bodmer, M.; Burki, S.; Boyen, F.; Haesebrouck, F.; Deprez, P.; et al. A new predilection site of Mycoplasma bovis: Postsurgical seromas in beef cattle. Vet. Microbiol. 2016, 186, 67-70. [CrossRef]

3. Djebala, S.; Evrard, J.; Moula, N.; Gille, L.; Bayrou, C.; Eppe, J.; Casalta, H.; Sartelet, A.; Bossaert, P. Comparison between generalised peritonitis and parietal fibrinous peritonitis in cows after caesarean section. Vet. Rec. 2020, 105867. [CrossRef] [PubMed]

4. Djebala, S.; Evrard, J.; Moula, N.; Sartelet, A.; Bossaert, P. Atypical case of parietal fibrinous peritonitis in a Belgian Blue heifer without a history of laparotomy. Vet. Rec. Case Rep. 2020, 8, e001086. [CrossRef]

5. Bourdette, P.; Mirbach, S.; Hoolbecq, M.; Plassard, V.; El-Bay, S.; Millemann, Y. "Clapier collé": Un cas original de péritonite chez une montbéliarde en France. Point. Vét. 2017, 372, 20-23.

6. Djebala, S.; Moula, N.; Bayrou, C.; Sartelet, A.; Bossaert, P.; Calixte, B.; Arnaud, S.; Philippe, B. Prophylactic antibiotic usage by Belgian veterinarians during elective caesarean section in Belgian blue cattle. Prev. Vet. Med. 2019, 172, 104785. [CrossRef] 
7. Mijten, P. Puerperal Complications After Cesarean Section in Dairy Cows and in Double-Muscled Cows. Reprod. Domest. Anim. 1998, 33, 175-179. [CrossRef]

8. Lamain, G.; Touati, K.; Rollin, F. La peritonite fibrineuse parietale: Une complication dans l'espèce bovine. In Proceedings of the Groupement Technique Vétérinaire Conference, Nante, France, 26-28 May 2012; pp. 237-240.

9. Lamain, G.; Touati, K.; Rollin, F. Aseptic fibrinous parietal peritonitis in cattle: Retrospective and clinical study. In Proceedings of the European Buiatrics Forum Conference, Marseille, France, 1-3 December 2009; p. 115.

10. Donofrio, G.; Flammini, C.F.; Scatozza, F.; Cavirani, S. Detection of Bovine Herpesvirus 4 (BoHV-4) DNA in the Cell Fraction of Milk of Dairy Cattle with History of BoHV-4 Infection. J. Clin. Microbiol. 2000, 38, 4668-4671. [CrossRef]

11. Bellino, C.; Iussich, S.; Biasato, I.; Peletto, S.; Caruso, C.; Gianella, P.; Cagnasso, A.; D'Angelo, A. Potential Pathogenetic Role of Bovine Herpesvirus 4 in Two Dairy Cows with Dermatitis-Pyrexia-Hemorrhagic Syndrome. J. Clin. Microbiol. 2015, 53, 2763-2767. [CrossRef]

12. Szymańska-Czerwińska, M.; Niemczuk, K.; Jodełko, A. Evaluation of qPCR and phase I and II antibodies for detection of Coxiella burnetii infection in cattle. Res. Vet. Sci. 2016, 108, 68-70. [CrossRef]

13. Association Régionale de Santé et d'Identification Animales (Annual Report). Available online: https: //www.arsia.be/wp-content/uploads/documents-telechargeables/RA-2017-light-Quality.pdf (accessed on 25 May 2020).

14. Delooz, L.; Czaplicki, G.; Houtain, J.Y.; Pozzo, F.D.; Saegerman, C. Laboratory Findings Suggesting an Association Between BoHV-4 and Bovine Abortions in Southern Belgium. Transbound. Emerg. Dis. 2016, 64, 1100-1109. [CrossRef] [PubMed]

15. Wellemans, G.; Antoine, H.; Broes, A.; Charlier, G.; van Opdenbosch, E. Symptomatologie variée apparaissant lors de métrites chroniques associées au virus herpès chez les bovins. Ann. Méd. Vét. 1984, 128, 65-74.

16. Koskinen, M.; Wellenberg, G.; Sampimon, O.; Holopainen, J.; Rothkamp, A.; Salmikivi, L.; van Haeringen, W.; Lam, T.; Pyorala, S. Field comparison of real-time polymerase chain reaction and bacterial culture for identification of bovine mastitis bacteria. J. Dairy Sci. 2010, 93, 5707-5715. [CrossRef] [PubMed]

17. Di Gioia, D.; Mazzola, G.; Nikodinoska, I.; Aloisio, I.; Langerholc, T.; Rossi, M.; Raimondi, S.; Melero, B.; Rovira, J. Lactic acid bacteria as protective cultures in fermented pork meat to prevent Clostridium spp. growth. Int. J. Food Microbiol. 2016, 235, 53-59. [CrossRef] [PubMed]

18. Mijten, P.; van den Bogaard, A.E.J.M.; Hazen, M.J.; de Kruif, A. Bacterial contamination of fetal fluids at the time of caesarean section in the cow. Theriogenology 1996, 97, 513-521.

19. Mohammed, A.N. Field study on evaluation of the efficacy and usability of two disinfectants for drinking water treatment at small cattle breeders and dairy cattle farms. Environ. Monit. Assess. 2016, 188, 151-162. [CrossRef]

20. Rzewuska, M.; Kwiecień, E.; Chrobak-Chmiel, D.; Kizerwetter-Świda, M.; Stefańska, I.; Gieryńska, M. Pathogenicity and Virulence of Trueperella pyogenes: A Review. Int. J. Mol. Sci. 2019, 20, 2737. [CrossRef]

21. Credille, B.; Woolums, A.; Giguère, S.; Robertson, T.; Overton, M.; Hurley, D. Prevalence of Bacteremia in Dairy Cattle with Acute Puerperal Metritis. J. Vet. Intern. Med. 2014, 28, 1606-1612. [CrossRef]

22. Kolenda, R.; Burdukiewicz, M.; Schierack, P. A systematic review and meta-analysis of the epidemiology of pathogenic Escherichia coli of calves and the role of calves as reservoirs for human pathogenic E. coli. Front. Microbiol. 2015, 5, 1-12. [CrossRef]

23. Fecteau, G. Management of peritonitis in cattle. Vet. Clin. N. Am. Food Anim. Pract. 2005, 21, $155-171$. [CrossRef]

24. Jones, S.I.; Smith, B.P. Disease of the alimentary tract. In Large Animal Internal Medicine, 5th ed.; Smith, B.P., Ed.; Elsevier: St. Louis, MO, USA, 2015; pp. 638-842.

25. Ducharme, N.G.; des Rochers, A.; Fubini, S.L.; Pease, A.P.; Mizer, L.A.; Walker, W.; Trent, A.M.; Roy, J.-P.; Rousseau, M.; Radcliffe, R.M.; et al. Surgery of the Bovine Digestive System. In Farm Animal Surgery; Elsevier BV: Amsterdam, The Netherlands, 2017; pp. 223-343.

26. Sheldon, I.M.; Williams, E.J.; Miller, A.N.; Nash, D.; Herath, S. Uterine diseases in cattle after parturition. Vet. J. 2008, 176, 115-121. [CrossRef] [PubMed] 
27. Tamai, I.A.; Mohammadzadeh, A.; Salehi, T.Z.; Mahmoodi, P. Genomic characterisation, detection of genes encoding virulence factors and evaluation of antibiotic resistance of Trueperella pyogenes isolated from cattle with clinical metritis. Antonie Leeuwenhoek 2018, 111, 2441-2453. [CrossRef] [PubMed]

28. Engels, M.; Ackermann, M. Pathogenesis of ruminant herpesvirus infections. Vet. Microbiol. 1996, 53, 3-15. [CrossRef]

29. Raoult, D.; Marrie, T.; Mege, J. Natural history and pathophysiology of Q fever. Lancet Infect. Dis. 2005, 5, 219-226. [CrossRef]

30. Maunsell, F.P.; Woolums, A.; Francoz, D.; Rosenbusch, R.; Step, D.; Wilson, D.; Janzen, E. Mycoplasma bovis Infections in Cattle. J. Vet. Intern. Med. 2011, 25, 772-783. [CrossRef]

31. Yang, B.; Li, Y.; Pascottini, O.; Xie, J.; Wei, R.; Opsomer, G.; Nauwynck, H. Primary replication and invasion of the bovine gammaherpesvirus BoHV-4 in the genital mucosae. Vet. Res. 2017, 48, 83. [CrossRef] [PubMed]

32. Zhang, R.; Han, X.; Chen, Y.; Mustafa, R.; Qi, J.; Chen, X.; Hu, C.; Chen, H.; Guo, A. Attenuated Mycoplasma bovis strains provide protection against virulent infection in calves. Vaccine 2014, 32, 3107-3114. [CrossRef]

33. Czaplicki, G.; Houtain, J.Y.; Mullender, C.; Porter, S.R.; Humblet, M.F.; Manteca, C.; Saegerman, C. Apparent prevalence of antibodies to Coxiella burnetii ( $Q$ fever) in bulk tank milk from dairy herds in southern Belgium. Vet. J. 2012, 192, 529-531. [CrossRef]

34. Wellemans, G.; van Opdenbosch, E.; Mammerickx, M. Inoculation expérimentale du virus LVR 140 (HERPÈS BOVIN IV) à des vaches gestantes et non-gestantes. Ann. Rech. Vét. 1986, 17, 89-94.

35. Haapala, V.; Pohjanvirta, T.; Vähänikkilä, N.; Halkilahti, J.; Simonen, H.; Pelkonen, S.; Soveri, T.; Simojoki, H.; Autio, T. Semen as a source of Mycoplasma bovis mastitis in dairy herds. Vet. Microbiol. 2018, 216, 60-66. [CrossRef]

36. Pardon, B.; de Bleecker, K.; Dewulf, J.; Callens, J.; Boyen, F.; Catry, B.; Deprez, P. Prevalence of respiratory pathogens in diseased, non-vaccinated, routinely medicated veal calves. Vet. Rec. 2011, 169, 278. [CrossRef] [PubMed]

37. Czaplicki, G.; Thiry, E. An association exists betweenbovine herpesvirus-4 seropositivity and abortion in cows. Prev. Med. Vet. 1998, 33, 233-240. [CrossRef]

38. Klamminger, S.; Prunner, I.; Giuliodori, M.; Drillich, M. Uterine infection with bovine herpesvirus type 4 in dairy cows. Reprod. Domest. Anim. 2016, 52, 115-121. [CrossRef] [PubMed]

39. Kreizinger, Z.; Szeredi, L.; Bacsadi, Á.; Nemes, C.; Sugár, L.; Varga, T.; Sulyok, K.M.; Szigeti, A.; Ács, K.; Tóbiás, E.; et al. Occurrence of Coxiella burnetii and Chlamydiales species in abortions of domestic ruminants and in wild ruminants in Hungary, Central Europe. J. Vet. Diagn. Investig. 2015, 27, 206-210. [CrossRef]

40. Frazier, K.; Pence, M.; Mauel, M.J.; Liggett, A.; Hines, M.E.; Sangster, L.; Lehmkuhl, H.D.; Miller, D.; Styer, E.; West, J.; et al. Endometritis in postparturient cattle associ-ated with bovine herpesvirus-4 infection: 15 Cases. J. Vet. Diagn. Investig. 2001, 13, 502-508. [CrossRef]

41. Donofrio, G.; Cavirani, S.; van Santen, V.L.; Flammini, C.F. Potential Secondary Pathogenic Role for Bovine Herpesvirus 4. J. Clin. Microbiol. 2005, 43, 3421-3426. [CrossRef]

(C) 2020 by the authors. Licensee MDPI, Basel, Switzerland. This article is an open access article distributed under the terms and conditions of the Creative Commons Attribution (CC BY) license (http://creativecommons.org/licenses/by/4.0/). 